\title{
J1-M267 Y lineage marks climate-driven pre-historical human displacements
}

\author{
Sergio Tofanelli ${ }^{*}, 14$, Gianmarco Ferri ${ }^{2,14}$, Kazima Bulayeva ${ }^{3}$, Laura Caciagli ${ }^{1}$, Valerio \\ Onofri $^{4}$, Luca Taglioli ${ }^{1}$, Oleg Bulayev ${ }^{3}$, Ilaria Boschi ${ }^{5}$, Milena Alù ${ }^{2}$, Andrea Berti ${ }^{6}$, \\ Cesare Rapone $^{6}$, Giovanni Beduschi ${ }^{2}$, Donata Luiselli ${ }^{7}$, Alicia M Cadenas ${ }^{8}$, \\ Khalid Dafaallah Awadelkarim ${ }^{9,10}$, Renato Mariani-Costantini ${ }^{10}$, Nasr Eldin Elwali ${ }^{9}$, \\ Fabio Verginelli ${ }^{10}$, Elena Pilli ${ }^{11}$, Rene J Herrera ${ }^{8}$, Leonor Gusmão ${ }^{12}$, Giorgio Paoli ${ }^{1}$ and \\ Cristian Capelli ${ }^{13}$
}

${ }^{1}$ Dipartimento di Biologia, Unità di Antropologia, University of Pisa, Pisa, Italy; ${ }^{2}$ Dipartimento Integrato di Servizi Diagnostici e di Laboratorio e di Medicina Legale, University of Modena e Reggio Emilia, Modena, Italy; ${ }^{3}$ Research Group of Human Genetic Adaptation, Vavilov Institute of General Genetics, Russian Academy of Sciences, Moscow, Russia; ${ }^{4}$ Dipartimento di Neuroscienze, Sezione di Medicina Legale, Università Politecnica delle Marche, Ancona, Italy; ${ }^{5}$ Istituto di Medicina Legale, Università Cattolica, Rome, Italy; ${ }^{6}$ Reparto Carabinieri Investigazioni Scientifiche di Roma, Sezione di Biologia, Rome, Italy; ${ }^{7}$ Dipartimento di Biologia Sperimentale ed Evoluzionistica, University of Bologna, Bologna, Italy; ${ }^{8}$ Department of Molecular and Human Genetics, College of Medicine, Florida International University, Miami, FL, USA; ${ }^{9}$ Department of Molecular Biology and Oncology, Institute of Nuclear Medicine, Molecular Biology and Oncology (INMO), University of Gezira, Wad Medani, Sudan; ${ }^{10}$ Unit of Molecular Pathology and Genomics, Center for Sciences on the Ageing (CeSI), 'G D'Annunzio' University Foundation, Chieti, Italy; ${ }^{11}$ Laboratori di antropologia, University of Florence, Florence, Italy; ${ }^{12}$ IPATIMUP, Instituto de Patologia e Imunologia Molecular da Universidade do Porto, Porto, Portugal; ${ }^{13}$ Department of Zoology, University of Oxford, Oxford, UK

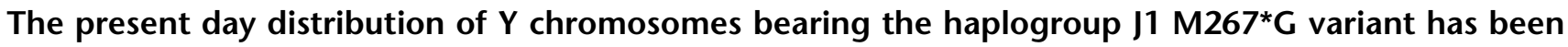
associated with different episodes of human demographic history, the main one being the diffusion of Islam since the Early Middle Ages. To better understand the modes and timing of $\mathrm{J1}$ dispersals, we reconstructed the genealogical relationships among $282 \mathrm{M} 267^{*} \mathrm{G}$ chromosomes from 29 populations typed at 20 YSTRs and 6 SNPs. Phylogenetic analyses depicted a new genetic background consistent with climate-driven demographic dynamics occurring during two key phases of human pre-history: (1) the spatial expansion of hunter gatherers in response to the end of the late Pleistocene cooling phases and (2) the displacement of groups of foragers/herders following the mid-Holocene rainfall retreats across the Sahara and Arabia. Furthermore, J1 STR motifs previously used to trace Arab or Jewish ancestries were shown unsuitable as diagnostic markers for ethnicity.

European Journal of Human Genetics (2009) 17, 1520-1524; doi:10.1038/ejhg.2009.58; published online 15 April 2009

Keywords: Y chromosome; haplogroup J1; human population history; Holocene

*Correspondence: Dr Sergio Tofanelli, Dipartimento di Biologia, Unità di Antropologia, University of Pisa, Via Ghini 5, Pisa, Italy.

Tel: + 39050 2211346; Fax: + 39050 2211475;

E-mail: stofanelli@biologia.unipi.it

${ }^{14}$ Joint authorship: Tofanelli Sergio and Ferri Gianmarco contributed equally to the paper.

Received 1 December 2008; revised 6 February 2009; accepted 6 March 2009; published online 15 April 2009
Introduction

Human Y chromosomes bearing the $M 267^{*} \mathrm{G}$ variant (defining haplogroup J1) are distributed over a vast area comprising Europe, South-western Asia, the Arabian peninsula, North and East Africa. Eight downstream SNPs have been identified so far along the $\mathrm{J} 1$ genealogy, ${ }^{1}$ none of which reaches appreciable frequencies in any population. 
Many authors have proposed STR-based motifs to trace the genealogies of pre-historic or ethno-religious ancestries. Examples are the Dys $388^{\star} 13$ allele associated with early neolithic agro-pastoral cultures (King RJ and Underhill $\mathrm{P}$, personal communication); the Galilee and the Dys388*17/YCAIIa/b*22-22 motifs for an Arab ancestry, ${ }^{2,3}$ the Cohanim 6-locus motif to link the descendants of a Jewish priesthood. ${ }^{4}$ However, a wide range of times since the most recent common ancestor (TMRCAs) has been proposed for $\mathrm{J} 1$ and its subclades (between 36 and $10 \mathrm{KyBP})$, and different conflicting scenarios have been depicted to explain their current distribution. ${ }^{3,5-9}$

\section{Materials and methods}

We surveyed the variation at 20 STR loci and at 6 SNPs in $282 \mathrm{~J} 1 \mathrm{Y}$ chromosomes of native unrelated donors from 29 populations. Ethnic data, genotyping protocols, quality standards, details of data analyses and haplotypes are provided as supplemental material (Supplementary Tables S1-6).

\section{Results and discussion}

A fine-grained map of the present day distribution of J1 chromosomes is given in Figure 1 . The pattern is uneven, as is typical of $\mathrm{Y}$ lineages with a very deep genealogy and low-size demes. Frequency peaks over $50 \%$ of the whole binary variation are present in Arabia (Yemen, Qatar), Northern Caucasus (Dagestan), Sudan and in Negev Bedouins (Supplementary Table S1). Frequency is inversely correlated to haplotype diversity $\left(R^{2}=0.387, P<0.001\right.$, Supplementary Table S6), with Near Easterners showing the highest diversity, Dagestanians and Arabic Sudanese the lowest. No major J1 sublineage was defined by genotyped SNPs (Supplementary Table S1) confirming the need for future research efforts in this direction. Nevertheless, in the Amhara from Ethiopia, we found the very first case of a M368(xM367) chromosome, which supports the insertion of the paragroup $\mathrm{J} 1 \mathrm{e}^{*}$ in the latest $\mathrm{Y}$ haplogroup phylogeny. ${ }^{1}$

With the exception of the rare Palestinian modal haplotype, ${ }^{10}$ none of the previously described STR motifs resulted equal by descent, as they were found across ethnic groups with different cultural or geographic affiliation and in other lineages $\left(\mathrm{J} 2, \mathrm{I}^{*}\right)$ than $\mathrm{J} 1$. Such results make their use to trace ancestries of individuals or communities (ie, Arab or Jewish) inconclusive. Calculations under the coalescent model for J1 haplotypes bearing the Cohanim motif gave time estimates that place the origin of this genealogy around 6.2 Kybp (95\% CI: 4.5-8.6 Kybp), earlier than previously thought, ${ }^{4}$ and well before the origin of Judaism (David Kingdom, 2.0 Kybp).

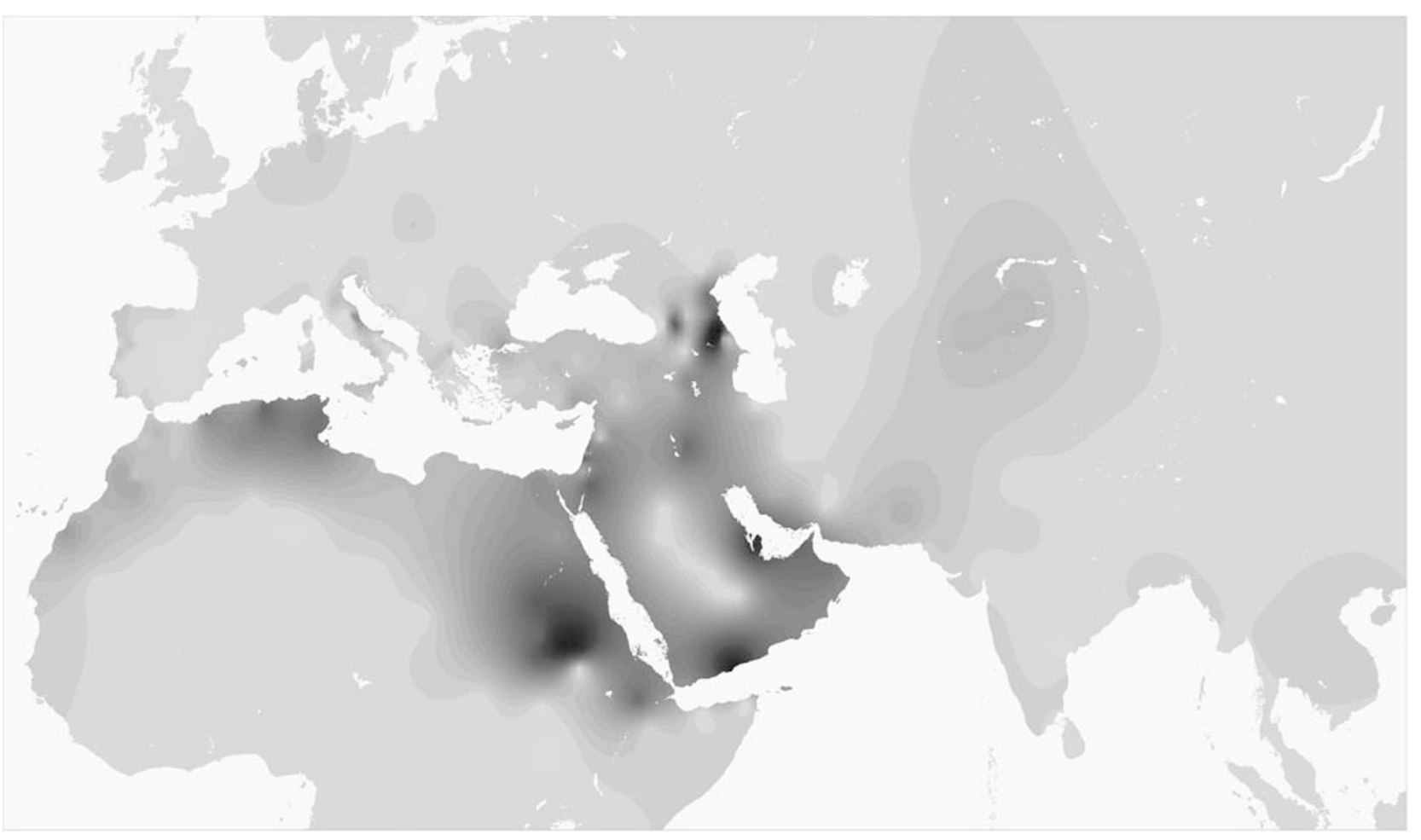

Figure 1 Contour map showing the present day distribution of $\mathrm{J} 1$ and $J^{*}(\mathrm{x} \mid 2)$ chromosomes. Gridding was carried out starting from 336 frequency points (Supplementary Table S3) with SURFIT 2.1 (http://surfit.sourceforge.net/index.html). Spatial surfaces were computed using GMT 4.3.1 (http://gmt.soest.hawaii.edu). Methodological details are available on request. 
Table 1 Descriptive and inferential statistics calculated for 20-locus haplotypes on 282 J1-M267 Y chromosomes

\begin{tabular}{|c|c|c|c|c|c|c|c|c|c|}
\hline & & & Mean pairwise & & & & Median TMRC & $A(95 \% \mathrm{Cl})$ & $\begin{array}{c}\text { Median } \mathrm{N}_{e} \\
\text { Constant size+ }\end{array}$ \\
\hline & $\mathrm{N}$ & $\%^{\mathrm{a}}$ & $\begin{array}{l}\text { difference (sum of } \\
\text { size difference) }\end{array}$ & Mode & $R^{\mathrm{b}}$ & $P^{c}$ & $\begin{array}{l}\text { Constant } \\
\text { size }\end{array}$ & $\begin{array}{l}\text { Population } \\
\text { growth }\end{array}$ & $\begin{array}{l}\text { population } \\
\text { growth }\end{array}$ \\
\hline $\begin{array}{l}\text { Tunisia } \\
\text { Morocco }\end{array}$ & $\begin{array}{l}18 \\
10\end{array}$ & $\begin{array}{l}30.1 \\
10.0\end{array}$ & $\begin{array}{l}3.93 \pm 2.83 \\
3.98 \pm 2.32\end{array}$ & $\begin{array}{l}1 \\
5\end{array}$ & $\begin{array}{l}0.019 \\
0.023\end{array}$ & $\begin{array}{l}0.002 \\
0.063\end{array}$ & $6799(4227-10826)$ & & \\
\hline $\begin{array}{l}\text { Iraq } \\
\text { Qatar } \\
\text { Arabic Sudanese }\end{array}$ & $\begin{array}{l}15 \\
20 \\
26\end{array}$ & $\begin{array}{l}26.7 \\
58.3 \\
74.3\end{array}$ & $\begin{array}{l}6.13 \pm 2.32 \\
6.53 \pm 3.88 \\
5.51 \pm 2.46\end{array}$ & $\begin{array}{l}6 \\
5 \\
5\end{array}$ & $\begin{array}{l}0.014 \\
0.020 \\
0.016\end{array}$ & $\begin{array}{l}N D \\
0.023 \\
0.021\end{array}$ & $7201(4553-12220)$ & $7150(6650-9650)$ & 477 \\
\hline Total J1-M267 & 282 & & & & & & $22537(6643-47439)$ & & 6485 \\
\hline $\begin{array}{l}\text { Clade/motif } \\
\text { Galilee }\end{array}$ & 56 & 18.4 & $4.07 \pm 2.19$ & 4 & 0.018 & 0.001 & $5510(3823-7747)$ & $5923(3766-9672)$ & 250 \\
\hline Dys388*17/YCAII*22-22 & 85 & 30.1 & $5.02 \pm 2.38$ & 4 & 0.013 & 0.000 & $6280(4762-7914)$ & $6113(2587-11138)$ & 314 \\
\hline Palestinian & 4 & 1.4 & $4.00 \pm 3.69$ & 17 & 0.306 & ND & & & \\
\hline Bedouin & 0 & 0.0 & & & & & & & \\
\hline
\end{tabular}

${ }^{\mathrm{a}}$ The frequency is referring either to the whole size of each population sample (for metapopulations) or the total of $282 \mathrm{~J} 1 \mathrm{chromosomes}$ (for motifs). ${ }^{\text {b}}$ Raggedness index. ${ }^{11}$

cprobability values of the goodness-of-fit test between observed mismatch counts and those expected under a model of sudden expansion; ${ }^{12}$ ND: not determined for sample size too low or variance $>$ mean.

Calculations for mismatch distributions, raggedness indexes and deviations from the Rogers' model were carried out by ARLEQUIN 2.0 (http:// anthropologie.unige.ch/arlequin). Median TMRCAs and median effective sizes $\left(N_{e}\right)$ were estimated by BATWING (http://www.mas.ncl.ac.uk/ nijw/) following the priors given in Supplementary Table S4.

Mismatch and multivariate analyses (Table 1, Figure 2) both pointed to common features for the Y chromosomes of Arabic speakers from Maghrib, Sudan, Iraq and Qatar (the Arabic pool). They show low diversity values, narrow mismatch curves with mode at 5-6 mutational steps and proximity at one side of the multidimensional genetic space. Opposite features were observed in a heterogeneous group, including Europeans, Kurds, Iranians and Ethiopians (the Eurasian pool); they show high haplotype diversity, are characterized by ragged mismatch curves with modes in the 11-16 range and cluster at the centre of the MDS plot. Omanis show a mix of Eurasian pool-like and typical Arabic haplotypes as expected, considering the role of corridor played at different times by the Gulf of Oman in the dispersal of Asian and East African genes. ${ }^{7}$

We wondered whether clustering and similarities among mismatch curves in the Arabic pool reflect shared evolutionary history, following the hypothesis of a diffusion of J1 chromosomes mediated by the spread of Islam since $650 \mathrm{AD} .^{2,3,9}$ To investigate this aspect in more detail, we compared the haplotype genealogy of the Eurasian and Arabic pools by using Median-joining networks constructed as described $^{9}$ (Figure 3 ). The genealogy of the Arabic pool shows a star-like pattern with no geographic 


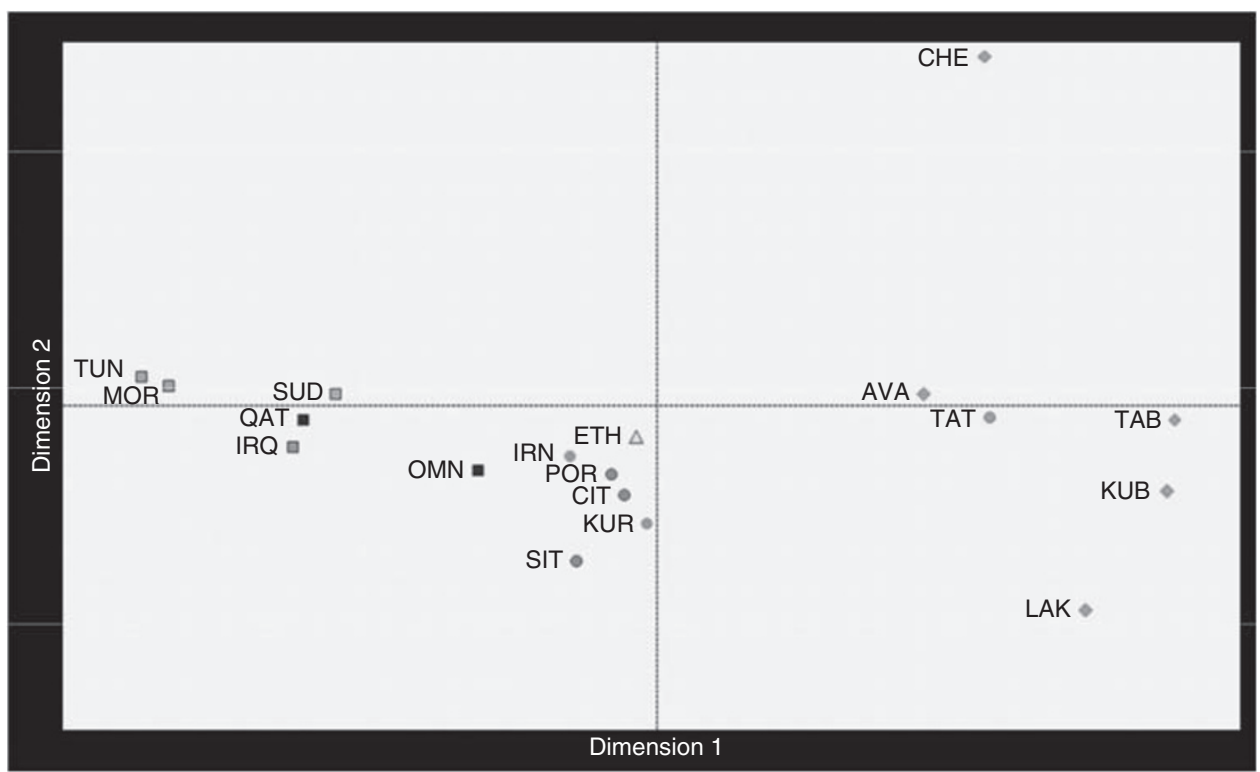

Figure 2 MDS plot of pairwise $F_{S T}$ distances among 18-locus haplotypes (alleles at duplicated loci Dys385a/b and YCAlla/b were pooled). Stress value $(0.07775)$ denotes a statistically significant departure from random structure. ${ }^{13}$ Dots colour: light blue $=$ Dagestan groups, black $=$ Arabian groups, Grey=Maghrebian groups, Purple =Sudanese groups, Green =European groups, Orange $=\mathrm{SW}$ Asian groups, Yellow $=$ Ethiopian groups . Dots' shape: squares =Arabic-speaking groups; circles=Indo-European-speaking groups; diamonds=North-Caucasian-speaking groups; triangleSemitic (non-Arabic)-speaking groups (the colour reproduction of this figure is available on the full text version of the manuscript).

structuring. This feature supports a demic expansion from ancestral haplotypes currently shared by Maghrebians and Arabians and subsequent migrations. The Eurasian genealogy is deeper and suggests a longer evolution under constant size. Accordingly, we assigned priors under different size models while applying a Bayesian approach ${ }^{14}$ to estimate coalescence times for samples' genealogies (Table 1). Results for Arabic populations and associated STR motifs (Galilee, Dys388*17/YCAII*22-22) excluded the timeline of the Arab expansion (1.35 KyBP), even from their lower confidence bounds, and pointed to a midHolocene time frame of 5.5-7.2 KyBP (median TMRCAs). This time window is related to a pre-historic phase of regionalisation in the human occupation of Sahara and Arabia, when semi-nomadic tribes, once diffused all over the Desert, retreated in water-rich refuges (ie, the Atlas range, ${ }^{15}$ the Sudanese plateau, ${ }^{16}$ Southern Arabia ${ }^{17}$ ) as a consequence of the rapid decline of monsoon rainfalls. In Eastern Sahara, it is associated with the rise of a dual productive economy, where specialised cattle pastoralism came to coexist with sedentary lifestyles, cereal farming and pottery production, clearly rooted in near East traditions. The genetic legacy of the mid-Holocene dispersal of foraging groups in the Sudanese Sahara, North Africa and Arabia would be tracked by Arabic J1-M267 chromosomes while the dispersal of agro-pastoralists with near eastern origins by other Y (E1b-M34 and E1b-M78 ${ }^{18}$ ) or mitochondrial $\left(\mathrm{U} 6 \mathrm{~b}^{19}\right)$ lineages.

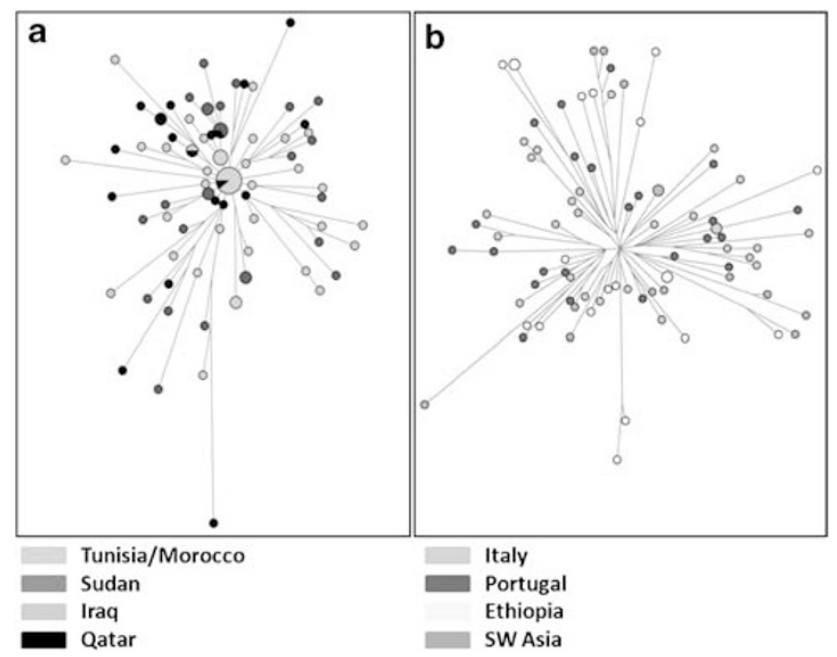

Figure 3 Network of 20-locus 11 haplotypes. (a) Arabic pool genealogy, (b) Eurasian pool genealogy. Area is proportional to frequency (the colour reproduction of this figure is available on the full text version of the manuscript).

As regards chromosomes bearing alleles Dys $388^{\star} 13$ and YCAIIa* $^{*} 19$, which are common in populations of the Eurasian pool and in Northern Caucasians, we, in general, obtained Late Pleistocene coalescence times - around 10.1-10.9 KyBP as average median values. These time estimates, summed to the high variation and wide 
distribution of these subclades, are consistent with the episodes of spatial re-expansion that occurred after the Last Glacial Maximum in the northern hemisphere, the latest being triggered by the end of the Younger Dryas event $\left(12.9-11.6 \mathrm{KyBP}^{20}\right)$. The different pattern observed (namely, frequency peaks in the Caucasus and Anatolia for Dys388*13, in Ethiopia and south-western Asia with the absence of haplotypes of the Arabic pool for YCAIIa*19) does not deviate from random expectations of frequency shifts under an extended Wright-Fisher model $(P \gg 0.05)$.

To resume, our results clearly reject the scenario put forward so far of a strict correlation between the Arab expansion in historical times and the overall pattern of distribution of J1-related chromosomes. Similarly, the causal association between STR-defined haplotypes and ethnic groups appear without any robust support, making its use inadequate for forensic or genealogical purposes. Instead, J1 variation provided the genetic background to correlate climatic changes to human demographic and socio-cultural events scarcely documented in the archaeological record the dispersal of hunter gatherers after the termination of glacial conditions in the late Pleistocene and the desertification-driven retreat of tribes of Saharan and Arabian foragers in the transition to a food-producing economy.

\section{Acknowledgements}

We thank Davide Merlitti for his precious support in the computational design. Publication of this study was made possible by the $60 \%$ grants to GP and ST by the University of Pisa. CC is a RCUK academic fellow. The collaboration with the University of Gezira is within the framework of the activities developed by the Center of Excellence on Aging (CeSI) of Chieti, Italy, as Special Consultant of ECOSOC of the United Nations.

\section{References}

1 Karafet TM, Mendez FL, Meilerman MB, Underhill PA, Zegura SL, Hammer MF: New binary polymorphisms reshape and increase resolution of the human $\mathrm{Y}$ chromosomal haplogroup tree. Genome Res 2008; 18: 830-838.

2 Nebel A, Landau-Tasseron E, Filon D, Oppenheim A, Faerman M: Genetic evidence for the expansion of Arabian tribes into the Southern Levant and North Africa. Am J Hum Genet 2002; 70: $1594-1596$.

3 Semino O, Magri C, Benuzzi G et al: Origin, diffusion and differentiation of Y-chromosome haplogroups $\mathrm{E}$ and J: inferences on the neolithization of Europe and later migratory events in the Mediterranean area. Am J Hum Genet 2004; 74: 1023-1034.

4 Thomas MG, Skorecki K, Ben-Ami H, Parfitt T, Bradman N Goldstein DB: Origins of Old Testament priests. Nature 1998; 394: $138-140$.

5 Di Giacomo F, Luca F, Popa LO et al: Y chromosomal haplogroup J as a signature of the post-neolithic colonization of Europe. Hum Genet 2004; 115: 357-371.

6 Arredi B, Poloni ES, Paracchini S et al: A predominantly Neolithic origin for Y-chromosomal DNA variation in North Africa. Am J Hum Genet 2004; 75: 338-345.

7 Cadenas AM, Zhivotovsky LA, Cavalli-Sforza LL, Underhill PA Herrera RJ: Y-chromosome diversity characterizes the Gulf of Oman. Eur J Hum Genet 2008; 16: 374-386.

8 Zalloua PA, Xue Y, Khalife J et al: Y-chromosomal diversity in Lebanon is structured by recent historical events. Am J Hum Genet 2008; 82: 873-882.

9 Chiaroni J, King RJ, Underhill P: Correlation of annual precipitation with human $\mathrm{Y}$ chromosome diversity and the emergence of Neolithic agriculture and pastoral economies in the fertile crescent. Antiquity 2008; 82: 281-289.

10 Nebel A, Filon D, Weiss D et al: High-resolution Y chromosome haplotypes of Israeli and Palestinian Arabs reveal geographic substructure and substantial overlap with haplotypes of Jews. Hum Genet 2000; 107: 630-641.

11 Harpending HC: Signature of ancient population growth in a low-resolution mitochondrial DNA mismatch distribution. Hum Biol 1994; 66: 591-600.

12 Rogers A: Genetic evidence for a Pleistocene population explosion. Evolution 1995; 49: 608-615.

13 Sturrock K, Rocha J: A multidimensional scaling stress evaluation table. Field methods 2000; 12: 49-60.

14 Wilson IJ, Balding DJ: Genealogical inference from microsatellite data. Genetics 1998; 150: 499-510.

15 Cheddadi R, Lamb HF, Guiot J, van der Kaars S: Holocene climatic change in Morocco: a quantitative reconstruction from pollen data. Clim Dyn 1998; 14: 883-890.

16 Kuper R, Kröpelin S: Climate-controlled Holocene occupation in the Sahara: motor of Africa's evolution. Science 2006; 313: 803-807.

17 Edens C, Wilkinson TJ: Southwest Arabia during the Holocene: recent archaeological developments. J World Prehist 1998; 12: $55-119$.

18 Cruciani F, LaFratta R, Santolamazza P et al: Phylogeographic analysis of haplogroup E3b (E-M215) Y chromosomes reveals multiple migratory events within and out of Africa. Am J Hum Genet 2004; 74: 1014-1022.

19 Maca-Meyer N, González AM, Pestano J, Flores C, Larruga JM, Cabrera VM: Mitochondrial DNA transit between West Asia and North Africa inferred from U6 phylogeography. BMC Genet 2003; 16: $4-15$.

20 Firestone RB, West A, Kennett JP et al: Evidence for an extraterrestrial impact 12,900 years ago that contributed to the megafaunal extinction and the Younger Dryas cooling. Proc Natl Acad Sci USA 2007; 104: 16016-16021.

Supplementary Information accompanies the paper on the European Journal of Human Genetics website (http://www.nature.com/ejhg) 